\title{
Human alveolar macrophages predominately express combined classical M1 and M2 surface markers in steady state

Elena Mitsi ${ }^{1}$, Raphael Kamng'ona², Jamie Rylance ${ }^{1}$, Carla Solórzano ${ }^{1}$, J. Jesus Reiné1 , Henry C. Mwandumba ${ }^{1,2}$, Daniela M. Ferreira ${ }^{1 \dagger}$ and Kondwani C. Jambo $0^{1,2^{*}+}$

\begin{abstract}
Alveolar macrophages (AM) are critical to the homeostasis of the inflammatory environment in the lung. Differential expression of surface markers classifies macrophages to either classically (M1) or alternatively activated (M2). We investigated the phenotype of human alveolar macrophages (AM) in adults living in two different geographical locations: UK and Malawi. We show that the majority of AM express high levels of M1 and M2 markers simultaneously, with the M1/M2 phenotype being stable in individuals from different geographical locations. The combined M1/M2 features confer to AM a hybrid phenotype, which does not fit the classic macrophage classification. This hybrid phenotype may confer to alveolar macrophages an ability to quickly switch between M1 or M2 associated functions allowing for appropriate responses to stimuli and tissue environment.
\end{abstract}

\section{Introduction}

The healthy human alveoli are dominated by alveolar macrophages (AM) [1]. These cells play a critical role in regulating immune responses [2] and maintaining homeostasis in the lung $[1,3]$. Their plasticity to adapt to changes in their microenvironment is fundamental in retaining the lung health [4]. Macrophages have been categorised as "polarised" towards either M1 (proinflammatory, mediating resistance to pathogens), or M2 mode (anti-inflammatory, promoting tissue remodelling) [5]. This categorisation is derived from murine models, and from in vitro polarisation of human macrophages using a combination of cytokines. However, whether AM polarisation in steady state fits the traditional M1/M2 dichotomy is still not well understood. We therefore investigated human AM polarisation in steady state, and ascertained the stability of the phenotype in two geographical locations and following in vivo exposure to bacterial and viral stimuli.

\footnotetext{
* Correspondence: Kondwani.Jambo@|stmed.ac.uk

${ }^{\dagger}$ Equal contributors

'Department of Clinical Sciences, Liverpool School of Tropical Medicine, Liverpool, UK

${ }^{2}$ Malawi Liverpool Wellcome Trust Clinical Research Programme, College of Medicine, P.O Box 30096, Chichiri, Blantyre 3, Malawi
}

\section{Methods}

Briefly, in the UK, healthy, non-smoking participants aged 18-50 years were recruited from an ongoing study of the Experimental human pneumococcal challenge (EHPC) model [6]. A subset of 25 participants, 16 individuals who had become colonized (carriage + ) with Streptococcus pneumoniae, and 9 who had not (carriage -) underwent research bronchoscopy at 4 to 7 weeks after the bacterial challenge. Alveolar macrophages were obtained from bronchoalveolar lavage (BAL), as described previously [7]. In Queen Elizabeth Central Hospital (QECH), Malawi, BAL samples [8] were obtained from selected asymptomatic adults ( $\geq 18$ yrs), comprising ten HIV-1-uninfected healthy controls and ten age-matched ART-naïve HIV-1infected individuals. We excluded participants with clinical evidence of active disease or recent history of severe respiratory illness.

Flow cytometry-based immunophenotyping was used to characterise AM phenotype obtained from BAL fluid. The expressional levels of key surface markers were measured immediately after sample collection.

(c) The Author(s). 2018 Open Access This article is distributed under the terms of the Creative Commons Attribution 4.0 International License (http://creativecommons.org/licenses/by/4.0/), which permits unrestricted use, distribution, and reproduction in any medium, provided you give appropriate credit to the original author(s) and the source, provide a link to the Creative Commons license, and indicate if changes were made. The Creative Commons Public Domain Dedication waiver (http://creativecommons.org/publicdomain/zero/1.0/) applies to the data made available in this article, unless otherwise stated. 


\section{Results}

Human alveolar macrophages simultaneously express M1 and M2 markers in steady state

Data from the two human cohorts from distinct geographical locations, UK (Additional file 1 Table S1) and Malawi (Additional file 1 Table S2), were collected independently and their comparison revealed a similar pattern of surface marker expression by AM. In both cohorts, the majority of AM were characterised as $\mathrm{CD} 206^{\mathrm{hi}} \mathrm{CD} 86^{\text {hi }}$. M1-like phenotype $\left(\mathrm{CD} 206^{\mathrm{lo}} \mathrm{CD} 86^{\mathrm{hi}}\right)$ and M2-like phenotype $\left(\mathrm{CD} 206^{\mathrm{hi}} \mathrm{CD} 86^{\mathrm{lo}}\right)$ subsets represented a small proportion (less than 1\%) of the total AM population (Fig. 1a and c). In addition, the $\mathrm{CD} 206^{\mathrm{hi}} \mathrm{CD} 86^{\mathrm{hi}}$ subset expressed greater levels of the M2 marker, CD163, compared to the M1 and M2 subpopulations (Fig. 1b and d). UK samples were further analysed for additional M1 markers (CD80, CD64) and an activation marker (HLADR). In these, the CD206 ${ }^{\text {hi }}$ CD $86{ }^{\text {hi }}$ subset expressed the highest levels of CD80, CD64 and HLADR expression in comparison to the other AM subsets (Fig. 1e-g).

\section{Colonization with pneumococcus does not alter the AM phenotype, whereas chronic HIV infection is associated with a lower expression of CD163 on CD206 ${ }^{\text {lo }} \mathrm{CD} 86^{\mathrm{hi}} \mathrm{AM}$}

We have previously shown that live intranasal pneumococcal challenge alters the alveolar environment by increasing the levels of pneumococcal-specific memory $\mathrm{CD}^{+}{ }^{+}$Th17 cells in the human lung [9], and that HIV infection disrupts the alveolar cytokine microenvironment [10]. We therefore investigated whether in vivo exposure to intranasal pneumococcal challenge or HIV infection polarise the AM phenotype. We compared experimentally pneumococcal-colonized individuals with non-colonized individuals, as well as, asymptomatic ART-naïve HIV-infected adults with age-matched HIV-uninfected healthy individuals. We found no difference in M1 or M2-like phenotype between individuals who became colonized following inoculation with S. pneumoniae compared with those who cleared the bacteria (Fig. 1a). Specifically, the expression of CD163 (Fig. 1b), CD80, CD64 and HLADR measured in the four AM subsets remain at the same levels between these groups (Fig. 1e-g).

Interestingly, in the Malawian population, AM subsets from HIV-infected individuals followed the same pattern of subdivision described in healthy volunteers. No difference was found in the proportion of the investigated subsets between the ART-naïve HIVinfected adults and HIV-uninfected healthy individuals (Fig. 1c). However, the expression of CD163 was significantly reduced in the $\mathrm{CD} 206^{\mathrm{lo}} \mathrm{CD} 86^{\mathrm{hi}}$ subset in HIV-infected individuals ( $p=0.0147)$ (Fig. 1d).

\section{Discussion}

In our study, we compared the polarisation of AM isolated from human volunteers from distinct geographical locations, UK and Malawi. We report that in healthy human pulmonary mucosa, AM adopt a hybrid phenotype, which shares features of both M1 (CD80, CD86, CD64) and M2 (CD206 and CD163) polarized macrophages. The same phenotype has been previously reported on the decidual macrophages (resident macrophages of the uterine lining), which exhibit characteristics of both proinflammatory and tolerogenic macrophages [11].

We also found that nasal pneumococcal colonization, even though it alters $\mathrm{CD}^{+} \mathrm{T}$ cell responses in the alveoli [9], does not alter the expression of key M1 and M2 polarization markers on the surface of AM. This leads to the speculation that a nasal pneumococcal exposure episode is either incompetent to modulate AM polarization or its effect is transient and quickly irreversible due to macrophages high plasticity [4]. By contrast, chronic HIV infection did affect the expression of CD163 on the M1-like AM subset $\left(\mathrm{CD} 206^{\mathrm{lo}} \mathrm{CD} 86^{\text {hi }}\right)$, with a lower expression of CD163 observed in HIVinfected individuals than HIV-uninfected controls. This finding is intriguing and may be due to active HIV infection of this alveolar macrophage subset [12] which has been shown to strongly repress CD163 expression on infected-macrophages [13]. Furthermore, CD163 is shed during activation as soluble CD163 (sCD163) [14] and this might in part explain the reduction of CD163 on the surface M1-like AM in HIV-infected individuals. However, even with in vivo exposure to pneumococci or HIV, the $\mathrm{CD} 206{ }^{\text {hi }} \mathrm{CD} 86^{\text {hi }}$ AM subset remained the major population, and this ascertains the stability of this phenotype.

Our data provides strong evidence suggesting that not all macrophages fall into M1 and M2 subsets. The major AM population in steady state expresses a duo M1/M2 phenotype. This phenotype is present in individuals from two distinct geographical location and is stable even after exposure to stimuli known to alter the alveolar environment. This is consistent with recent call for a rethink of the M1/M2 macrophage paradigm [5]. It is possible that the lack of stark polarisation is helpful in maintaining a healthy balance between immune tolerance and protective immunity in the alveolar space. However, whether other tissue macrophages, beyond decidual and alveolar macrophages, exhibit similar phenotypes in vivo warrants further investigation.

\section{Conclusion}

The clear majority of alveolar macrophages combine M1 and M2 features in steady state, a phenotype that may allow brisk and adaptive responsiveness to multiple elements in the local milieu. 
a

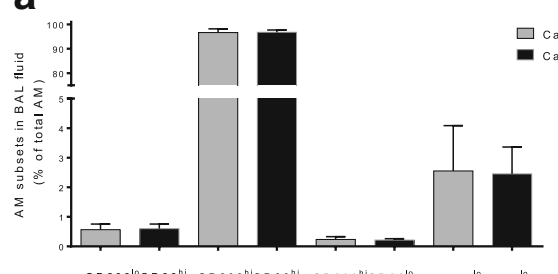

b

$\operatorname{CD} 206^{10} \mathrm{CD} 86^{\mathrm{hi}} \quad \operatorname{CD} 206^{\mathrm{hi}} \mathrm{CD} 86^{\mathrm{hi}} \quad \operatorname{CD} 206^{\mathrm{h}} \mathrm{CD} 86^{10} \quad \operatorname{CD} 206^{10} \mathrm{CD} 86^{10}$

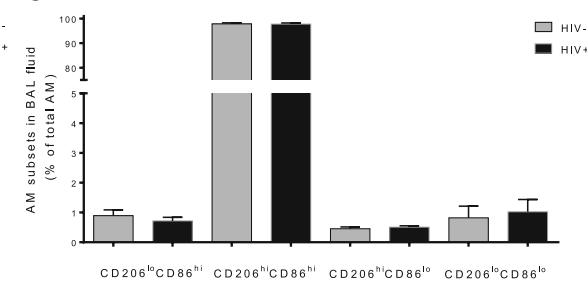

C

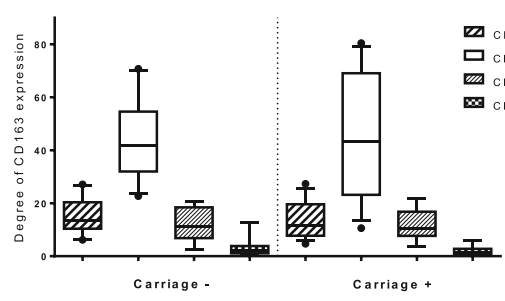

d

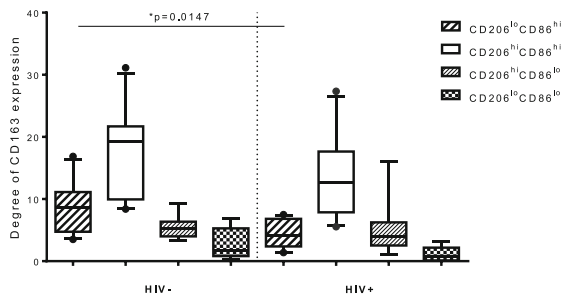

e

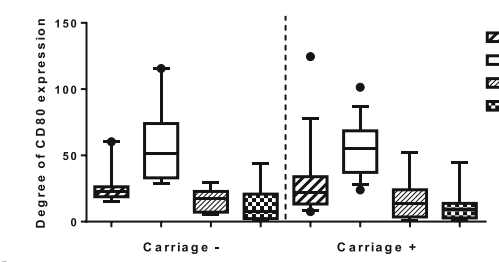

f

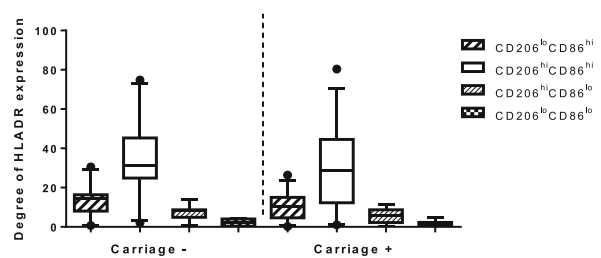

g

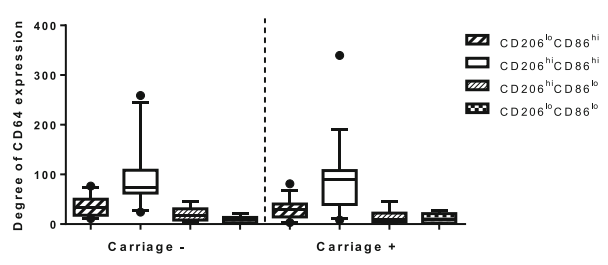

Fig. 1 Comparison of human alveolar macrophage phenotype between UK and Malawi healthy adults (a) Percentages of AM subsets gated for CD206 and CD86 (UK cohort, $n=9$ for grey bars and $n=16$ for black bars) and the (b) the degree of CD163 expression in each of the subsets. The data shows that $\mathrm{CD} 206^{\mathrm{hi}} \mathrm{CD} 86^{\mathrm{hi}}$ subset occupies the highest proportion and expresses the highest levels of CD163 when compared with the other three. $\mathbf{c}-\mathbf{d}$ The same pattern is observed on the AM derived from the healthy Malawian individuals (grey bars, $n=10$ ). The effect of pneumococcal colonization and HIV infection on AM polarisation. $\mathbf{a}-\mathbf{b}$ AM subsets are compared between non-colonized (carriage -) and colonized group (carriage +) post experimental nasal pneumococcal inoculation. There is no alteration of AM phenotype associated with nasal pneumococcal colonization. CD206 ${ }^{\text {hi }}$ CD86 ${ }^{\text {hi }}$ is the dominant subset with the highest CD163 expression amongst the rest $(p<0.0001$ when compared with $\mathrm{CD} 206^{\mathrm{lo}} \mathrm{CD} 86^{\mathrm{hi}}$ or $\mathrm{CD} 206^{\mathrm{hi}} \mathrm{CD} 86^{\mathrm{lo}}$. c AM subsets are compared between HIV-uninfected healthy adults $(\mathrm{n}=10)$ and HIV-infected individuals $(n=10)$. AM collected from HIV-infected individuals follows the same pattern with healthy HIV-uninfected individuals when gated for CD206 and CD86. $\mathbf{d ~ C D 2 0 6}{ }^{\text {hi }} \mathrm{CD} 86^{\text {hi }}$ is the dominant subset with the highest CD163 expression amongst the rest $\left(p<0.002\right.$ when compared with CD206 ${ }^{\text {lo }} \mathrm{CD} 86^{\mathrm{hi}}$ or CD206 ${ }^{\text {hi }} \mathrm{CD} 86^{\text {lo }}$ in both HIV-uninfected and HIV-infected individuals. However, the HIV infection regresses the expression of CD163 in the CD206 ${ }^{\text {lo }} \mathrm{CD} 86^{\text {hi }}$ subset. e-g Levels of CD80, CD64 and HLADR expression respectively between carriage negative and carriage positive individuals. There is no significant difference on levels of CD80, CD64 and HLADR expression mediated by nasopharynx pneumococcal colonization. Within-group comparisons used Wilcoxon tests, and between-cohort comparisons used Mann-Whitney $U$ test 


\section{Additional file}

Additional file 1: Table S1. Demographics of the EHPC study participants- UK. Table S2. Demographics of study participants - Malawi. Table S3. Summary of the panel composition at the UK site (no shading) and Malawi site (grey shading). Fig. S1. Gating strategy used to identify human alveolar macrophages in the UK Cohort. Fig. S2. Gating strategy used to identify human alveolar macrophages in the Malawi Cohort. (DOCX 681 kb)

\section{Abbreviations}

AM: Alveolar macrophage; BAL: Bronchoalveolar lavage

\section{Acknowledgments}

The authors gratefully would like to thank all participants who participated in this study, all staff of the Clinical Research Unit at the Royal Liverpool Hospital and Queen Elizabeth Central Hospital, as well as, the clinical staff of the Respiratory Infection Group at the Liverpool School of Tropical Medicine and Immunology Research Group at the Malawi-Liverpool-Wellcome Trust Clinical research programme (MLW).

\section{Funding}

This work was funded by Wellcome (UK) through an Intermediate Fellowship number 105831/Z/14/Z awarded to KCJ, the Bill and Melinda Gates Foundation (OPP1117728) and Medical Research Council (Grant number: MR/M011569/) grant awarded to D.M.F. The MLW is supported by a strategic award from the Wellcome.

\section{Availability of data and materials}

The datasets used and analysed during the current study will be available from the Liverpool school of Tropical Medicine online repository. This can be accessed via: http://archive.Istmed.ac.uk/

\section{Authors' contributions}

Conception and design: EM, HCM, JR, DMF, KCJ. Analysis and interpretation: EM, RK, JR, CDS, HCM, DMF, KCJ. Drafting the manuscript for important intellectual content: EM, HCM, JR DMF, KCJ.

\section{Ethics approval and consent to participate}

At the UK site, the study was approved by the NHS Research Ethics Committee (REC Reference 14/NW/1460). At the Malawi site, approved the study was approved by research ethics committee of Malawi College of Medicine, under approval number P.03/16/1907. All participants provided written informed consent.

\section{Competing interests}

The authors declare that they have no competing interests.

\section{Publisher's Note}

Springer Nature remains neutral with regard to jurisdictional claims in published maps and institutional affiliations.

Received: 9 March 2018 Accepted: 12 April 2018

Published online: 18 April 2018

\section{References}

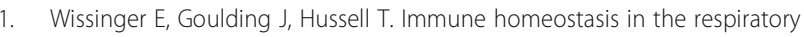
tract and its impact on heterologous infection. Semin Immunol. 2009; 21(3):147-55

2. Gordon SB, Read RC. Macrophage defences against respiratory tract infections. Br Med Bull. 2002:61:45-61.

3. Snelgrove RJ, Godlee A, Hussell T. Airway immune homeostasis and implications for influenza-induced inflammation. Trends Immunol. 2011 32(7):328-34.

4. Stout RD, Suttles J. Functional plasticity of macrophages: reversible adaptation to changing microenvironments. J Leukoc Biol. 2004;76(3):509-13.

5. Hussell T, Bell TJ. Alveolar macrophages: plasticity in a tissue-specific context. Nat Rev Immunol. 2014;14(2):81-93.
6. Gritzfeld JF, Wright AD, Collins AM, Pennington SH, Wright AK, Kadioglu A, Ferreira DM, Gordon SB. Experimental human pneumococcal carriage. J Vis Exp. 2013;(72):50115

7. Zaidi SR, Collins AM, Mitsi E, Reine J, Davies K, Wright AD, Owugha J, Fitzgerald R, Ganguli A, Gordon SB, et al. Single use and conventional bronchoscopes for Broncho alveolar lavage (BAL) in research: a comparative study (NCT 02515591). BMC Pulm Med. 2017;17(1):83.

8. Mtunthama N, Malamba R, French N, Molyneux ME, Zijlstra EE, Gordon SB. Malawians permit research bronchoscopy due to perceived need for healthcare. J Med Ethics. 2008;34(4):303-7.

9. Wright AK, Bangert M, Gritzfeld JF, Ferreira DM, Jambo KC, Wright AD, Collins AM, Gordon SB. Experimental human pneumococcal carriage augments IL-17A-dependent T-cell defence of the lung. PLoS Pathog. 2013; 9(3):e1003274

10. Jambo KC, Tembo DL, Kamng'ona AW, Musicha P, Banda DH, Kankwatira AM, Malamba RD, Allain TJ, Heyderman RS, Russell DG, et al. HIV-associated disruption of lung cytokine networks is incompletely restored in asymptomatic HIV-infected Malawian adults on antiretroviral therapy. ERJ Open Res. 2017;3(4):00097-2017.

11. Quillay H, El Costa H, Marlin R, Duriez M, Cannou C, Chretien F, Fernandez $\mathrm{H}$, Lebreton A, Ighil J, Schwartz O, et al. Distinct characteristics of endometrial and decidual macrophages and regulation of their permissivity to HIV-1 infection by SAMHD1. J Virol. 2015;89(2):1329-39.

12. Jambo KC, Banda DH, Kankwatira AM, Sukumar N, Allain TJ, Heyderman RS, Russell DG, Mwandumba HC. Small alveolar macrophages are infected preferentially by HIV and exhibit impaired phagocytic function. Mucosal Immunol. 2014;7(5):1116-26.

13. Porcheray F, Samah B, Leone C, Dereuddre-Bosquet N, Gras G. Macrophage activation and human immunodeficiency virus infection: HIV replication directs macrophages towards a pro-inflammatory phenotype while previous activation modulates macrophage susceptibility to infection and viral production. Virology. 2006;349(1):112-20.

14. Burdo TH, Lentz MR, Autissier $P$, Krishnan A, Halpern E, Letendre $S$, Rosenberg ES, Ellis RJ, Williams KC. Soluble CD163 made by monocyte/ macrophages is a novel marker of HIV activity in early and chronic infection prior to and after anti-retroviral therapy. J Infect Dis. 2011;204(1):154-63.

\section{Ready to submit your research? Choose BMC and benefit from:}

- fast, convenient online submission

- thorough peer review by experienced researchers in your field

- rapid publication on acceptance

- support for research data, including large and complex data types

- gold Open Access which fosters wider collaboration and increased citations

- maximum visibility for your research: over $100 \mathrm{M}$ website views per year

At BMC, research is always in progress.

Learn more biomedcentral.com/submissions 